\title{
More than the eye can see: Left ventricular global longitudinal strain assessment in a patient with takotsubo cardiomyopathy within a 9-month follow-up
}

\author{
Sonia J Konsek-Komorowska, Piotr Cygański, Andrzej Rynkiewicz \\ Department of Cardiology and Internal Medicine, School of Medicine, Collegium Medicum, University of Warmia and Mazury in Olsztyn, Olsztyn, Poland
}

\author{
Correspondence to: \\ Sonia J Konsek- \\ -Komorowska, \\ Department of Cardiology \\ and Internal Medicine, \\ School of Medicine, \\ Collegium Medicum, \\ University of Warmia \\ and Mazury in Olsztyn \\ Aleja Warszawska 30, \\ 10-082 Olsztyn, Poland, \\ phone: +48 895245389 , \\ e-mail: \\ sonia.konsek@interia.pl \\ Copyright by the Author(s), \\ 2021 \\ Kardiol Pol. 2021; \\ 79 (7-8): 887-888; \\ DOl: 10.33963/KP.a2021.0018 \\ Received: April 28, 2021 \\ Revision accepted: \\ May 23, 2021 \\ Published online: \\ May 24, 2021
}

Takotsubo cardiomyopathy (TTC) is a cardiac condition characterized by acute but reversible left ventricular (LV) dysfunction in the absence of obstructive coronary artery disease [1-3]. Two-dimensional (2D) speckle-tracking echocardiography (STE) is a useful method for evaluating global and regional left ventricular function and is consistently more sensitive than conventional echocardiography in detecting minor myocardial abnormalities [1]. The utility of STE in TTC patients has been described in a few short-term reports [1-4], however, there is limited understanding around the time course of functional recovery in TTC patients [1]. In this article, we present a case of a 30-year-old female with a sequential evaluation of global longitudinal strain (GLS) during a 9-month follow-up.

The patient with a history of supraventricular tachycardia was admitted to the hospital with chest pain radiating to the left arm. An electrocardiogram showed sinus rhythm with $T$ wave inversion and QT prolongation. High-sensitivity troponin $\mathrm{T}$ and the concentration of $\mathrm{N}$-terminal brain natriuretic propeptide were moderately elevated. Transthoracic echocardiography (TTE) revealed hypokinesis/akinesis of new apical segments and the apex. Compared to a routine TTE performed 4 months before the admission to the hospital, LV ejection fraction (LVEF) decreased from $70 \%$ to $50 \%$. 2D STE analysis showed a severe decline in longitudinal strain (LS) within all apical segments and the apex, as well as a mild decline within mid-cavity segments, with reduced GLS from $26.9 \%$ to $18.7 \%$ (Figure $1 \mathrm{~A}-\mathrm{B}$ ). Coronary angiography showed no abnormalities. Based on the patient's clinical features, along with electrocardiogram and echocardiographic abnormalities in the absence of coronary lesions, a typical apical ballooning TTC was diagnosed. The patient was treated with zofenopril, propranolol, spironolactone, and atorvastatin for 9 months. Subsequent control TTEs were performed on the $5^{\text {th }}$ and $15^{\text {th }}$ day of hospitalization (Figure $1 \mathrm{C}$ and D), as well as at 5 (Figure 1E), and 9 months after admission to the hospital (Figure 1F) revealing progressive improvement to LV contractile function. LVEF returned to the normal range of $70 \%$ within 5 months (Supplementary material, Video S1) and a GLS of $25.9 \%$ within 9 months. Interestingly, the control 2D STE assessment revealed that although LS in apical segments had been impaired for just a short time (LS drop from $28.2 \%$ to $10 \%$ ), mid-cavity and basal segments were also affected - however to a lesser extent, but for a prolonged duration (LS drop from $28 \%$ to $19.2 \%$ and from $25.7 \%$ to $21.2 \%$, respectively) (Figure 1A). Not all changes were easily noticeable in conventional 2D echocardiography and suggest a slow, gradually spreading process.

In our report, we describe a case of TTC with changing LV systolic function assessed by LVEF and GLS throughout the acute and subacute phases (lasting approximately 1 month) and gradual recovery to baseline over the following 8 months. Our report is consistent with other studies reporting the presence of subtle LV dysfunction, even after the normalization of LVEF $[1,3]$. To our knowledge, this is the first case reported in the literature showing the long-term sequential evaluation of GLS in a TTC patient. Further analysis of correlation of segmental myocardial deformation using strain-encoded cardiac magnetic resonance imaging (SENC) and STE could be useful [5]. 

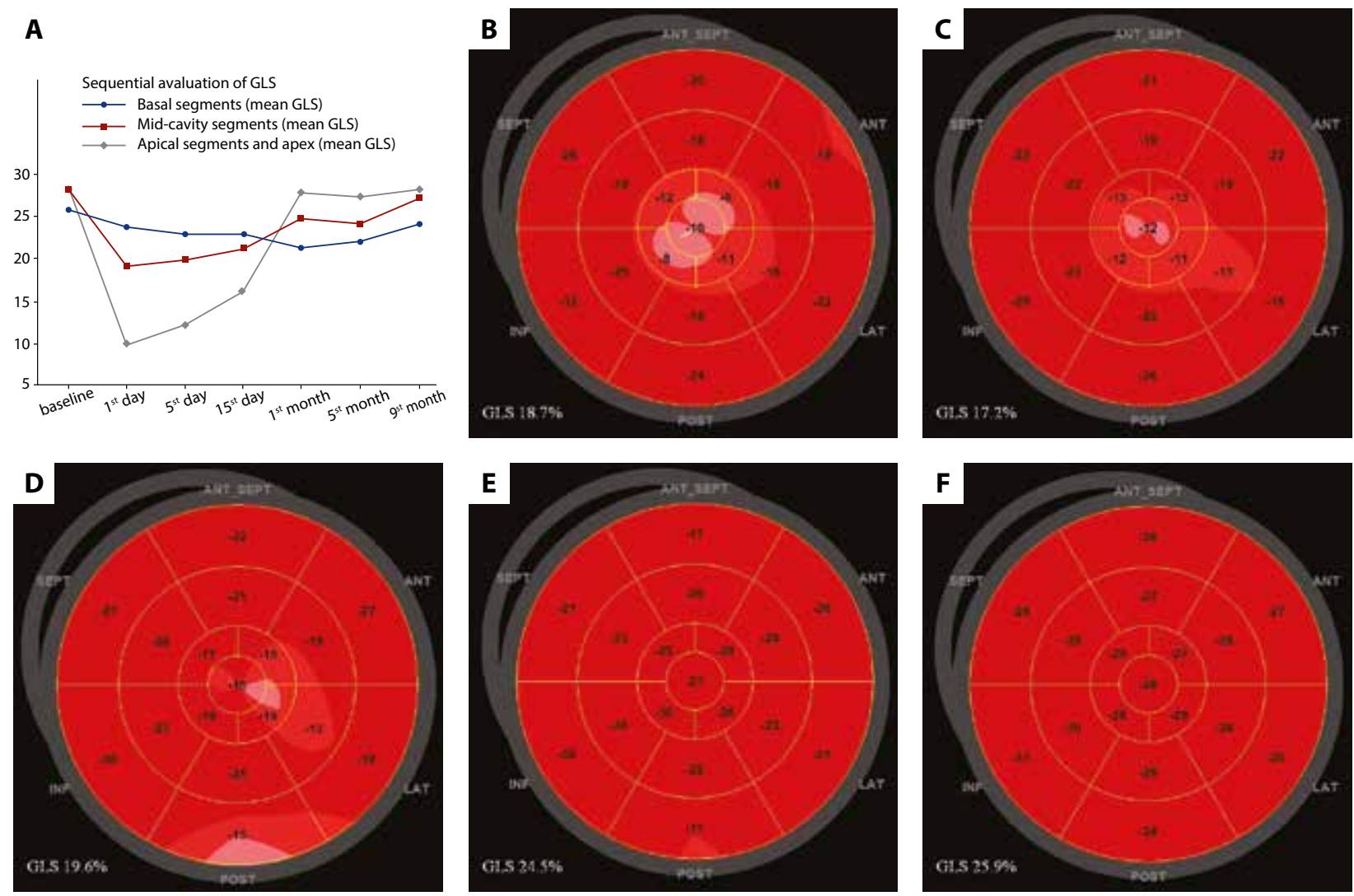

Figure 1. GLS assessment. A. Sequential evaluation of GLS from baseline (4 months before diagnosis of TTC) through and during 9 months follow-up. B. The day of hospital admission - severe segmental decline in longitudinal strain within all apical segments and apex, with the concomitant mild decline within mid-cavity segments. C. $5^{\text {th }}$ day of hospitalization - a progressive segmental decline of longitudinal strain within mid-cavity and basal segments of the inferolateral wall with a slight improvement in all apical segments and apex. D. $15^{\text {th }}$ day of hospitalization - improvement in longitudinal strain within the apical segments, apex, and mid-cavity segments, excluding mid-cavity segments of the anterolateral and inferolateral wall. E. 5 months after hospital admission - continuous slight improvement in longitudinal strain within all previously impaired segments. F. 9 months after admission to the hospital - full improvement in longitudinal strain within all segments compared to baseline

Abbreviations: GLS, global longitudinal strain; TTC, takotsubo cardiomyopathy

\section{Supplementary material}

Supplementary material is available at https://journals. viamedica.pl/kardiologia_polska.

\section{Article information}

\section{Conflict of interest: None declared.}

Open access: This article is available in open access under Creative Common Attribution-Non-Commercial-No Derivatives 4.0 International (CC BY-NC-ND 4.0) license, allowing to download articles and share them with others as long as they credit the authors and the publisher, but without permission to change them in any way or use them commercially. For commercial use, please contact the journal office at kardiologiapolska@ptkardio.pl.

How to cite: Konsek-Komorowska SJ, Cygański P, Rynkiewicz A. More than the eye can see: Left ventricular global longitudinal strain assessment in a patient with Takotsubo Cardiomyopathy within a 9-month follow-up. Kardiol Pol. 2021; 79(7-8): 887-888, doi: 10.33963/KP.a2021.0018.

\section{REFERENCES}

1. Lee M. Time course of functional recovery in takotsubo (stress) cardiomyopathy: a serial speckle tracking echocardiography and electrocardiography study. J Cardiovasc Imaging. 2020; 28(1): 50-60, doi: 10.4250/jcvi.2019.0083, indexed in Pubmed: 31997608.

2. Nowak R, Fijalkowska M, Gilis-Malinowska $N$, et al. Left ventricular function after takotsubo is not fully recovered in long-term follow-up: A speckle tracking echocardiography study. Cardiol J. 2017; 24(1): 57-64, doi: 10.5603/CJ.a2017.0001, indexed in Pubmed: 28070881.

3. Kim SA, Jo SH, Park KH, et al. Functional recovery of regional myocardial deformation in patients with takotsubo cardiomyopathy. J Cardiol. 2017; 70(1): 68-73, doi: 10.1016/j.jjcc.2016.09.006, indexed in Pubmed: 27889396.

4. Dias $A$, Franco $E$, Rubio $M$, et al. Usefulness of left ventricular strain analysis in patients with takotsubo syndrome during acute phase. Echocardiography. 2018; 35(2): 179-183, doi: 10.1111/echo.13762, indexed in Pubmed: 29171097.

5. Konishi T, Funayama N, Yamamoto T, et al. Acute anterior myocardial infarction complicated by takotsubo syndrome: the value of multimodality imaging. Kardiol Pol. 2020; 78(10): 1055-1056, doi: 10.33963/KP.15492, indexed in Pubmed: 32633477. 